Helena Rill

DOI: https://doi.org/10.18485/slovenika.2020.6.1.6

Centar za nenasilnu akciju (CNA)

Beograd, Srbija

helena.rill@gmail.com

Lada Stevanović

Etnografski institut SANU

Beograd, Srbija

lada.stevanovic@gmail.com
UDK: 316.728:314.15.044-055.2(497.4)(093.3)

392.61(497.4:497.11)(093.3)

Pregledni rad

\title{
Kompleksne putanje ljudskih sudbina: mogu li se naučno prepoznati?
}

\section{Sažetak}

Tekst predstavlja uvodno i teorijsko razmatranje istraživanja migracija (iz Slovenije u Srbiju) metodom usmenih intervjua, tj. razgovora vođenih sa ženama u okviru projekta usmenih istorija, koje je započela Helena Rill. Projekat i razgovori osmišljeni su tako da razotkriju „drugu“, tj. intimnu stranu medalje migracija koja se ne zadovoljava javnim narativima o brojkama, datumima i itinerarijima koje migranti prelaze. Polazeći od pojma migracije srca, koji je uveo etnolog Dušan Drljača ${ }^{1}$ kao termin koji se odnosi na selidbe motivisane ljubavlju, $u$ radu se predlaže proširivanje značenja pojma i ukazuje na činjenicu da svaka migracija, bila ona prinudna ili dobrovoljna, iznenadna ili dugo planirana, ostavlja trajne promene i tragove na ljudskoj duši. Značajno za razumevanje ličnih i individualnih sećanja ispovesti jeste i to što su ona često daleko komplikovanija i teže uklopiva $\mathrm{u}$ javne narative. To je razlog iz kog se razmatraju i pojmovi pamćenja kao kolektivnog fenomena (kreiranog odozgo) i sećanja kao intimnog, ličnog i pojedinačnog.

Ključne reči: migracije, usmene istorije, žene, sećanje

Pitanja migracija su oduvek bila aktuelna. Posebno su obeležila XX vek, prelivajući se i u ovo stoleće. Nažalost, mnoge od njih su prisilne i njima smo bili, a i dalje smo svedoci. Međutim, ima i drugačijih migracija i na njima će biti akcenat. Postoji jedan termin koji

\footnotetext{
${ }^{1}$ Termin je kod nas preuzet sedamdesetih godina prošlog veka iz poljske literature.
} 
je u neformalnim razgovorima koristio etnolog Dušan Drljača, a koji bi barem o jednoj vrsti migracija mogao biti rečitiji već iz samog naslova, a to su migracije srca. Reč je o selidbama zbog ljubavi. Ipak, postavlja se pitanje nisu li sve migracije zapravo migracije srca i duše, ne donosi li svaka selidba unutrašnje bure i velike promene koji god da je razlog. Svako izmeštanje, bilo dobrovoljno, a posebno prinudno, promrda našu bazu - pa se pitamo gde nam je temelj, a šta podrška, gde je taj kontinuitet življenja, ponovo postavljamo pitanja šta je to važno i kakva je poveznica između mesta gde smo živeli i ovde gde smo sada. U medijima i statističkim analizama, svejedno, svodi se sve na cifre: koliko je preseljeno, koji je postotak. U knjigama takođe možemo da nađemo razna objašnjenja, faktografski nabrojane događaje, ali retko se desi da osetimo šta stoji iza toga.

Zato želimo da opipamo puls i osetimo šta to stoji iza tih brojki, koje su to ljudske priče. Jedan od načina da to učinimo jesu usmene istorije i lični narativi, a posebno nas interesuje ona ženska strana koja je manje prisutna u javnom prostoru prepunom brojki i analiza. Ovde nam je bitno - šta je to što stoji u pozadini, šta žene imaju da kažu o svojim odlukama, o tome šta tamo ostavljaju, a šta nalaze ovde, kako podnose to, šta nose sa sobom. Jasno je da one sa sobom ponesu (neke) bitne stvari, fotografije, komad nameštaja, starog medu ili nakit, ali one ujedno nose čitav svet sa sobom, svet uspomena i vrednosti. Ono „tamo“ je Slovenija, a ovo „ovde“ je Srbija i pitanje je - šta je to stiglo i šta čine novi prostor i novi život, kako se ono „slovenačko“ i ono „srpsko“, kako god ih definisali, prepliću u našim životima.

$\mathrm{U}$ akademskim istraživanjima intervju i usmene istorije su se iz polja etnologije i antropologije proširile na istoriju i druge humanističke discipline. Naročito značajne, usmene istorije postale su za rodne i ženske studije. Iz ovih raznovrsnih istraživanja i problematizovanih pitanja, koja su se počela pojavljivati, pokrenuta je potpuno nova istraživačka oblast, koja se naziva studijama sećanja, a bavi se ne samo sakupljanjima različitih sećanja već i pitanjima i problemima koji utiču na kompleksne mehanizme kroz koje se pamćenje i sećanje oblikuju. Renata Jambrešić Kirin naglasila je da, za razliku od engleskog jezika, koji poznaje samo termin memory, postoje jezici koji prave razliku između individualnog sećanja i kolektivnih mehanizama koji generišu pamćenje. Nijansu u značenju ova dva termina autorka primećuje upravo u tome što je sećanje lično, neposredovano, korporealno, intimno, dok pamćenje predstavlja kolektivni fenomen, kontrolisano je i generisano odozgo. 
Zato je pamćenje ispisano (u udžbenicima, štampi, muzejima, javnom prostoru, spomenicima), a sećanje je najčešće usmeno, osim u dnevničkim zapisima ili autobiografijama (Jambrešić Kirin 2008, 46). Interesantno je da i sama leksika razotkriva razliku između dva navedena termina, jer sećati se možemo samo nečega što je vezano za prošlost, a pamćenje je dvosmerno - možemo pamtiti prošlost, ali možemo učiti i (u)pamtiti nešto za budućnost (Stevanović 2009, 102).

U čemu je uistinu značaj individualnih sećanja za nauku? Pre svega u korektivu, u proširivanju perspektive i u davanju mogućnosti da se čuju glasovi drugih - u ovom slučaju žena. Njihovi su glasovi i njihova sećanja svakako različiti i kompleksniji od zvaničnih, ali i suvoparnih istorija ili kolektivnih pamćenja, brojki i statistika. To su prepoznale feminističke epistemologije i zbog toga su usmene istorije, ali i životne priče (kao celovite autobiografije) postale veoma značajne, pa je muškoj priči (his story - history), koja se dugo smatrala jedinom relevantnom, dodata i ženska priča (her story). ${ }^{2}$ Najzaslužnije za razvoj i razrađivanje specifične metodologije za organizovano sakupljanje usmenih istorija i životnih priča žena bile

\footnotetext{
${ }^{2}$ Pomenućemo neke od publikacija: Znamenite žene Novog Sada, prir. Gordana Stojaković (2001), Romkinje: biografije starih Romkinja u Vojvodini, prir. Svenka Savić, Marija Aleksandrović, Stanka Dimitrov, Jelena Jovanović (2001, na srpskom i romskom; 2002, na engleskom jeziku), Neda: jedna biografija; životna priča Nede Božinović, prir. Gordana Stojaković (2002), Žene sa Kosova: životne priče Albanki, prir. Elizabet Kesli (2002), Životne priče Rusinki, prir. Marija Tot i Veronika Mitro sa Irinom Gardi-Kovačević, Slavicom Senderak i Karolinom Džudžar (2003, na rusinskom i srpskom jeziku), Životne priče Slovakinja u Vojvodini, prir. Antonija Ferkova, Jarmila Hodoličova, Ana Jaškova, Veronika Mitro (2003, na slovačkom i na srpskom), Životne priče vojvođanskih Mađarica, prir. Svenka Savić i Veronika Mitro (2006), Jevrejke: životne priče žena iz Vojvodine, prir. Edita Jankov (2006), Romkinje 2, prir. Svenka Savić (2007), Jelica Rajčić Čapaković, prir. Svenka Savić (2007), Hrvatice, Bunjevke, Šokice, prir. Svenka Savić (2007), „A što ću ti ja jadna pričat...", prir. Svenka Savić, Veronika Mitro, Sara Savić, Marijana Čanak (2008), Životne priče žena sa invaliditetom u Vojvodini, prir. Milica Bracić, Milica Mima Ružičić Novković, Svenka Savić (2009), Zašto su ćutale majka i ćerka u istom ratu, prir. Magda Simin Bošan, Nevena Simin (2009), Životne priče žena u Vojvodini - Rumunke, prir. Laura Spariosu, Svenka Savić (2011), Profesorke Univerziteta u Novom Sadu - životne priče, prir. Svenka Savić, Erika Marjaš, prir. Svenka Savić (2018). Sve ove knjige objavile su Ženske studije iz Novog Sada, većina ih sadrži kompletne životne priče, a neke samo delimično sadrže usmene istorije, poput Erike Marjaš, nastale kao sinteza životne priče i različitih intervjua i sakupljenih podataka. Pored toga, ovakva istraživanja odvijala su se i nezavisno od ovog Centra. Svakako treba istaći knjigu Miroslave Malešević, Didara, životna priča jedne Prizrenke (2004). Tu su i publikacije Dunavske Švabice, prir. Nadežda Ćetković, Dobrila Sinđelić-Ibrajter (2000), Dunavske Švabice II, prir. Nadežda Radović, Dobrila Sinđelić-Ibrajter i Vesna Weiss (2001). Pored toga, metode životnih priča i usmenih istorija koriste se i u radu na izgradnji mira. Vidi npr. Slike tih vremena: životne priče veterana/veteranki i članova/članica njihove porodice, ur. Helena Rill i Tamara Šmidling (2010).
} 
su Svenka Savić i njene koleginice i saradnice okupljene oko udruženja Ženske studije i istraživanja, kao i u okviru univerzitetskog programa Rodnih studija u Novom Sadu. Bilo da je reč o usmenim istorijama, životnim pričama ili kombinovanim istraživanjima biografskih i autobiografskih, usmenih i pisanih izvora, istraživački rezultati su fantastični.

Svaki segment, svaka lična priča, svaka pojedinačna istorija, pored topline i taloga sećanja, nosi sa sobom bogatstvo, koje upotpunjuje zvanične narative. Uzeti zajedno, oni stvaraju jednu celinu, koja pruža mogućnost za uvid u kompleksne putanje ljudskih sudbina.

Kad pročitate razgovor koji sledi, on je mnogo više od intervjua, a manje od cele životne priče. Reč je o tome da čitamo kako se nečeg sećamo, čega se sećamo, šta nam je bitno u datom trenutku. Uprkos geografskom izmeštanju, imamo taj tok, kontinuitet starog i novog, povezujemo se sa svojim roditeljima, sa svojim majkama i bakama, $\mathrm{i}$ nosimo ih sa sobom, u prenesenom smislu, u nov kraj i tu se nastavlja njihov kontinuitet; svoju staru zemlju utkivamo u novu i imamo tugu, ali i bogatstvo. Ovaj razgovor je jedinstven, kao i svaka druga priča, i tako je treba gledati. Ono što je univerzalno jeste da svaka od nas nosi čitav svoj univerzum menjanjem svog mesta i sveta.

Obe autorice ovog teksta takođe imaju iskustvo na relaciji Slovenija-Srbija, polazišne osnove su različite, konteksti takođe, ali osećaji pripadnosti, ili otuđenosti, prepoznavanja i traženja su obema bliski - nošenje svog identiteta, različitosti, privikavanja, podrške, lepote onoga što nosimo sa sobom... što nam govori i intervju $u$ nastavku; mirisi i slike, odlasci u šetnju i razgovori sa bakom. Odjednom ta jedna brojka, „ta“ koja se preselila, jeste mnogo više od tog broja, to je čitav jedan svet, kao što pomenusmo već u ovom tekstu.

Ono što nas povezuje sa našom prošlošću i što će možda naše (potencijalne) potomke podsećati, kao i ono što, recimo, u ovom slučaju, povezuje Sloveniju i Srbiju, jeste ono što su žene vekovima radile kako bi održale sećanja živim gde god da se nalazile: ona se prenose kroz pričanja i ponovna prepričavanja, kroz njihovo pisanje, prenošenje porodičnih priča i anegdota, pevanja pesama, pretakanje tih reči koje se pretaču u prave slike. Ženski deo spoznavanja su ta sitna, a u stvari krucijalna tkanja gde god se mi nalazile. 


\section{Razgovor sa T. T. iz Slovenije ${ }^{3}$}

\section{Možete da se predstavite - šta biste rekli o sebi?}

Ja sam T. T., imam 32 godine i u Srbiji živim sad petu godinu. Inače sam iz Slovenije, moja cela porodica je iz Slovenije, po tom pitanju ništa interesantno... (smeh). Sve uglavnom „pravo“...

\section{Odakle ste?}

Sebenje. Sebenje je jedno malo selo blizu Tržiča, gorenjski deo Slovenije, tamo gde se nalaze Bohinj, Bled, Jesenice. Gde ima najviše gora i gde su gore najviše i pokrivene snegom. Moja porodica je započela tamo život, pa sam posle u mladosti otišla u Ljubljanu da studiram, i zatim sam se našla tu. To je sve što sam se zvanično premeštala.

Kako ste se preselili ovde, u Beograd, da li je to bila spontana odlu$k a$, nagla, ili posle puno premišljanja...?

$\mathrm{Na}$ kraju jesam odlučila naglo, ali ne može da se kaže da je to bilo neko ogromno iznenađenje s obzirom na to da sam se ja preselila zbog ljubavi, koja je već tada uveliko postojala, i bilo je zapravo logično rešenje da se neko preseli, a taj ko se preselio sam bila ja... (smeh). Ja se tome nisam nimalo protivila zato što mi je životna situacija u tom trenutku, pre pet godina, bila takva da ništa nije bilo, sem naravno mog srca i svega toga što me veže za Sloveniju, ništa zvanično, fakultet sam završila, ni posao nisam tamo našla, nisam imala svoju decu itd., tako da sam bila odmah za tu ideju da ja dođem. Bili smo dečko i ja već dugo zajedno, pa smo se godinama posećivali, zatim je on ovde našao stan i eto, spakovala kofere i došla (smeh).

\section{Da li je bila teška odluka reći „odoh ja sada“?}

Jeste, to sam videla tek posle, kad sam već bila tu, koliko mi je nedostajalo. U onom trenutku i ne toliko, zato što sam ja išla sa idejom da će biti to dve, maksimalno tri godine. Kad smo nas dvoje pričali je kod mene uvek stajalo - „možda može, ali maksimalno pet godina“. Naravno, pet godina prođe mnogo brže nego što sam zamišljala tako da mi nije bilo toliko teško jer sam sve vreme mislila jednom nogom tamo, jednom ovamo. Tako malkice naivno u smislu da može čovek da ima podjednako dva doma, što se ispostavi da ne može baš tako. Nije mi bilo teško da odem, nego su bili teški periodi kad dođe - šta sam uradila. Taj osećaj.

\footnotetext{
${ }^{3}$ Razgovor je prenet u originalu kako je vođen, red reči i leksika nisu menjani.
} 


\section{Šta je bilo teško?}

Meni je, pre svega, bilo teško zbog odnosa, zbog mojih ljudi koji su doboko u mom srcu. Ja sam iz veoma velike porodice, za ovo vreme. Imam tri rođene sestre i dva rođena brata. Mi smo jako povezani, baš-baš od malena. Nedostatak blizine ljudi koji me znaju u dušu, to mi je... to me i sad steže. Dosta sam drugarstva i prijateljstava, divne ljude ovde upoznala, ali kad te neko zna - zna, kad ne moraš ništa da objašnjavaš, samo ti vidi lice i zna, to mi je najžešće i najčešće nedostajalo. I sad se desi. I druga stvar, priroda. Priroda, priroda, to je taj osećaj slobode u prirodi, kretanje, akcije, udaha vazduha, da... to je možda ta kombinacija prastare ljubavi ljudi koji me znaju i te prirode, slobode, dubokog disanja, ta kombinacija mi stvara osećaj da mi baš nešto fali. Iako sam ovde stekla toliko toga što me ispunjuje...

Da, to potpuno razumem za ljude, ali i za to okruženje, koliko je u stvari jedno povezano sa drugim, ta naša emotivna, lična geografija, živim tamo, živim ovde, a u stvari je sve prepleteno...

To ste lepo rekli. Nešto što je meni zanimljivo - moja porodica i ja, i još poneki ljudi koji žive tu odakle sam ja, obožavamo kišu. Pre nego što krene, svi smo nešto nervozni, a kad jednom padne, kad krene da pljušti, mi smo svi, od prvog do posledjeg, aaah... dođemo sebi. To je ta povezanost geografije sa ljubavlju, jer na primer, ovde ne mogu da nađem budalu koja će da ide sa mnom kad je najgore napolju, još teže da uživa u tome, uglavnom ide: „Jesi ti luda, gde ćeš po ovome!?"

Šta radite kad vam nešto to nedostaje, od kuće, iz Slovenije?

Uglavnom šetam. Meni je to sve, navući neke patike i trenerku, prija mi da budem u seoskom izdanju (smeh), bez sređivanja, nego bukvalno patike i trenerka, bitno mi je da to bude samo šetnja za luftiranje, da nije ono usput još u prodavnicu, apoteku, nego baš šetnja. Po mogućnosti bez ičega, bez telefona, to mi uvek spašava dušu, u svim takvim trenucima kad mi je teško. Šetnja pogotovo kad je kiša, onda me to istušira iznutra, to mi pomaže. Pre svega, to. I tehnologija podržava naše odnose, pa tu mogu da zavrtim nečiji broj, i to mnogo znači. Jedna sestra, druga sestra, pa brat, mama... dok okrenem sve, i nedelja se okrenula, pa i moje raspoloženje. 
Imate blizu ovde neku prirodu?

Živim u centru, bukvalno dve ulice odavde. Nemam. Imam blizu do Tašmajdana, spustim se i do Dunava, ali nije pravi pojam prirode kad ne možeš da budeš sam. Kad bi se malo više aktivirala, da sednem u kola (nemam kola, ali to nije izgovor), ili u autobus, da se vozim tamo negde, verujem, na primer, tamo iza Ade, bila sam tamo i bude lepo, nego nekako je priroda dostupna samo preko tri prevoza. Gde možeš da dišeš, ta priroda. Baš kad sam opisivala kuću - tamo izletim napolje tačno $u$ tome što nosim, tačno kakva jesam, i odmah sloboda, odluka u mahu, to je ovde u ovom gradu teško. Ako hoćeš u prirodu, moraš da se isplaniraš, da nađeš prevoz, da sedneš, to je ta razlika. Ovo je baš veliki grad naspram Ljubljane. To mi je do sada najveći grad u kom sam živela, pa onda došla u Beograd, ima razlike. Tamo ti treba samo bicikla i grad je tvoj.

Šta ste to poneli od kuće, iz Slovenije, neki predmet, što vam je toplo i milo u srcu i podseća na dom?

Ponela sam gomilu stvari jer sam se selila, ali baš razmišljam šta bih da naglasim, razmišljala sam još juče. No, onda sam se osvrnula oko sebe i brzo se to uspostavi. To su tri predmeta koja su mi tako značajna... Jedan je knjiga stripova Miki Muster. Ne znam da li ste čuli, on je crtao još za vreme Jugoslavije, vrhunski striper, da tako kažem, crtao je stripove. Ali bitno je, zato što su to priče koje je nama zapravo čitao otac kad smo bile klinke, kad smo nas četiri još bile devojčice male - dečaka još nije bilo jer su oni najmlađi - i onda smo se sve skupčale oko njega, a on je ovako otvarao i čitao. Baš je bilo lepo, a za to su vezane i „insajd fore“, još dan-danas ga zezamo, prvo zato što je imao sklonost da čita čistim muškim glasom, dubokim i uvek pravim, a dijaloškost stripa to teško podnosi, i onda se pojavila neka smešna fora, pa je prestao da čita, pročita foru za sebe i krene da se smeeeje, a nas četiri - šta, šta, šta je bilo, reci, reci! Naravno, suštine toga šta je njemu bilo smešno, nikad nismo saznale. Nešto zbog naše mladosti, nešto zbog očevih tehnika čitanja, koje nisu trpele ponavljanja. Svi volimo te uspomene i pre par godina su mi za rođendan poklonili novo izdanje tog stripa i u njega napisali „za tvoje večito detinjstvo“. To je jedan predmet koji me baš podseća na nešto lepo. E sad, nešto sladunjavo, ali i dalje imam jednog medvedića, koji sam isto dobila na dan rođenja, mali plavi... Dugo mi je bilo glupo, šta ćeš medvedića da nosiš, malo mi je bilo onako premalo kul, a onda rekoh: sad sam dovoljno stara da me baš briga šta je kul i šta nije, ja hoću tog medvedića da imam. On mi 
je drag zato što je priča moje sestre, ona je druga redom, ja četvrta, a pošto smo se devojke rađale na godinu dana razlike, međusobno smo skoro pa vršnjakinje. I moja Ana još nije imala ni pune tri godine, mislim, kad sam se rodila i kad je rekla: „Tanica tud mora imet medvedka!"I ta sestra još dan-danas brine o meni, još tada kao bebu me prihvatila kao svoju, i dan-danas je tako. I to što se ona izborila da ja moram da imam tog medvedka, još mi nekakao ostaje... neka toplina odnosa. Imam i jednu zlatnu narukvicu, koju mi je dala baba, još jedan vrhunski lik u mom životu, baš-baš vrhunski lik, baba ima devedeset godina, živi sama i ona je jedna od mojih najboljih prijatelja na svetu. Ona je vrh od čoveka, od ljudskog bića. Na narukvici je ugravirana reč „mama“, pa to bude i za nju i za moju mamu, i nekad kad budem i ja mama, nadam se, i za mene. To je treća stvar. To bih mogla da predstavim kao stvari koje me vežu za Sloveniju i još za žene.

Kako te sve stvari nose uvek neku priču, odnose, i kako je to sve obojeno emocijama. A što je baka tako vrhunska?

Dobro pitanje. Vrhunska je zato što ja nju smatram da je umetnica života. To je ta generacija, poznato vam je, nikad žene nisu imale tu neku ličnu priču/priliku... žene sa sela, zna se kako se živi i šta će biti u životu. Bila je uvek dobra, mirna, tiha, čak i stroga i sve to, a onda... Ono što volim kod nje, ona nikad ni o kome nije ništa nažao rekla, kao da nema tu neku potrebu da bi kritikovala druge, potpuno odsustvo te osobine, a opet može da ima snažan stav, to mi je neverovatno. I drugo, ta radost, da si malo mangup, da voliš da se zezaš, da se smeješ, da bockaš na neki ljubazan način, to je sve ona, to je direktno išlo u našu porodicu, najradosniji čovek je i dan-danas. Sama radost, koliko god je boli, jedna noga kraća, dosta toga više ne radi kako treba, nijednom se nije požalila, nikada, i samo da može da se smeje, da se zeza, da zapeva, ona sa svojom energijom, ona je toliko sačuvala taj žar, a to kad je deda umro... To zvuči strašno. Deda je bio dobar čovek, samo što je ona živela tipičan život mame i babe, a onda kad je deda umro, sa dosta godina, ja sam je još uvek poznavala samo kao babu. Zatim ne znam šta mi bilo, rekoh iz vedrog neba: „Mama (mi je zovemo jednostavno mama), mogu jednom da te vodim na kafu u grad?" Može, ok, a meni je lepo da pričam sa njom, kao sa ženom, i onda je krenula navika koja traje još danas. Više ne idemo u grad jer je sada previše boli, nego ja dolazim kod nje. Kad god sam kući, ja donesem neki hlepčić za doručak, ona skuva kafu, sedimo sasvim blizu i guramo laktove zajedno, pa pričamo, plačemo, i smejemo se, mnogo se grlimo - toga je u životu imala premalo. 


\section{Kad je deka umro?}

Ja sam bila valjda treća godina gimnazije, ima više od 15 godina.

Više od 15 godina se družite na drugačiji način.

$\mathrm{Da}$, i osećam neverovatnu sreću i blagoslov, što sam mogla... srećom još je tu, ali ima 90 godina, tako neku silu od čoveka da upoznam i još da mi je rod... kad posmatram braću i sestre, sad mi je više stvari jasno... (smeh). Kao neću ništa više da komentarišem, i onda samo izbije iz njenih usta tako neka fora, kao da bi neko od nas to izgovorio... samo nas ostavi bez daha. Fino, fino i onda kaže nešto kao bocne tako duhovito i dobronamerno da prvo zinemo i tek za koji trenutak eksplodiramo u vrisku smeha, uvek občinjeni koliko je ona sila od čoveka... neverovatna je.

Dok ovo pričate, osećam se zahvalna na tome što ste otvorili vrata porodici i što mogu da je vidim. Kako se zove baka?

Baka se zove Ljudmila, zvanično, ali uvek je bila Milka, ali zanimljivo je, Milka je za ljude koji je ne poznaju tako dobro, odnosno za one iz crkve, sela i grada, ali za sve ostale, ona je mama. Ima petoro dece, mislim da 22 unuka, moram ponovo da izbrojim... (smeh), sad ima već pet praunuka, i ne samo što je cela porodica zove mama, nju mama zovu i svi oni koji su došli u porodicu, ona je prosto Mama. I pre nekog vremena - ja sam loša za brojeve, zaboravim ih brzo - ali baš sam joj izbrojala i kažem joj kad smo pile kafu: „Mama, jesi ti svesna koliko ljudi tebe zove isključivo mama?"I to je bio broj više od trideset ljudi. Mislim da je to vanredno. Svi hoćemo, svi biramo da je zovemo mama. Jednostavno mama.

\section{Ona obuhvata sve.}

A ne znam čime. Nekom svojom energijom, kao što rekoh, prati, prihvata, podržava, ništa ne pridikuje, ništa nažao ni o kome, i samim tim zapravo veže za sebe. Uopšte nije radoznala za svaku detajlu naših odluka, nego je opet interesujemo, interesuje je sve što je do života, sve što je drži u stopu sa nama, na primer, sasvim uredu koristi mobilni telefon. Kad bi me neko pitao ko mi je uzor ili kakva bih volela da postanem, rekla bih nju, baš zbog toga jer je stvarno umetnik života. Bez obzira na to ima li diplome ili nema, a nema, da li se proslavila u bilo kom smislu, ali ovakvu umetnost prema životu nisam videla. Nigde drugde. A nije da se nije namučila, nije imala lak život, ali neka snaga u njoj prosto zadivljuje... 
Ženama nije bilo lako u to vreme, mogu da zamislim šta su one sve nosile, posebno nekada u malim sredinama. Lepo je čuti kako cenite, poštujete ono što ona jeste, njenu životnu radost.

Jer kako se život odvija i kako ja odrastam, vidiš da je to zapravo najteže, po meni. Najlakše je postići uspeh takav onakav, nego uspeti da ti zadržiš radost, zahvalnost i neku lepotu srca i duše kroz ceo život i u starosti. To mi se čini većim od bilo kog uspeha koliko god neprimetno izgledalo. Vidim da život nije uvek lak i da ti uspeš da sačuvaš ono što je u tebi je stvarno... najlepše, ono dobro, stvarno prisno, ti si po meni onda uspeo. I još da imaš takvu porodicu, ona živi sama, ali okružena je porodicom. Ona je magnet, zbog tog svog karaktera, uglavnom svi volimo da idemo kod nje, baš baš volimo.

\section{Šta vas radovalo tamo, a šta raduje ovde?}

To što me radovalo tamo sam rekla, priroda, ljudi, a ovde, taman se sve dopunjuje. Ovde mi se sviđa neka živost, šarenolikost, ovde u Beogradu, imam osećaj da taj grad može da prihvati sve. To mi je, za razliku od mog doma u Sloveniji, i Slovenije uopšte, prelepo, ta neka vrsta otvorenosti, brzo se osećaš kao domać, dobro domaći nikad nećeš biti, ako ništa drugo naglasak te odmah odaje, ali nekako lako se stopiš sa masom u tom gradom, $\mathrm{u}$ lepom smislu, kao da možeš da duboko udahneš u smislu svog identiteta ko si, kakav si, kako pričaš, kako se oblačiš, to mi se, na primer, jako dopada u Beogradu, ili sam ja imala sreće da se krećem u takvim delovima. Mislim da je uopšte takav, šaren je i dopušta šarenilo. Pa ta ekspresivnost ljudi... Ta živost i ekspresivnost ljudi, to mi jako prija, ne znam odakle, ali živi u meni nešto od toga već odavno i činilo mi se da u Sloveniji nekako odudara, tamo je uglavnom sve svedenije, finije, ovde je sve na forte, što je nekad naporno, ali je i očaravajuće. I grad mi se sviđa zbog skrivenih atrija i uličica. Volim da se gubim po ovom gradu, i dan-danas, šetnja, i onda krenem i samo idem, nikad nemam neki pravac, meni se sviđa ta njegova lepa trpko-slatka raspadnutost. Znam da je to ružno reći, jer naravno svi želimo da sve dobro funkcionira, da se obnovi, ali nešto u tom ima šarma. I to, sve radi, sve je živo, sve je na dohvat ruke, taj osećaj stvarno velikog grada, odakle sam ja došla sve radi do pet... I da ne zaboravim, do sada sam upoznala nemalo stvarno dobrih ljudi. Kad dođeš u određene godine, osećaš da ne možeš da stekneš više tako lako neka nova drugarstva, nekako se promeni, e i sad kad se osvrnem oko sebe, u ovim godinama, ja sam našla dosta njih koji će biti za ceo život. I tako (pod)oživljavamo Jugoslaviju (smeh). Malo se šalim, ali sam takođe malo ozbiljna. Većina 
nas je rođena još u toj državi, moja generacija i moji drugari, nisu to prazne reči, koliko god nismo doživeli tu mladost u Jugoslaviji, ipak je ostalo neko kolektivno sećanje, neka blizina. Često se šalimo kad sedimo tako zajedno, ja, pa ljudi odavde, pa nađemo nekog Makedonca ili Crnogorca ili Bosanca... pa se nasmejemo na naš račun.

\section{Šta možete reći o mami?}

Mama. Moja mama je drugačiji karakter, isto je divna duša, više je nemiran duh, stalno se razvija, radi na sebi, energična je ko živo srebro, istinska žena-borac... Ona ima tu neverovatnu ljubav prema deci. Što je očigledno, je l', rodila nas je poprilično dosta (smeh). Ali stvarno je magična za decu, neverovatno kakava je ta žena, ima petoro unuka, i dalje ide na posao, i sad kad je gledam, mi joj svi kažemo - ti si čudo. Ona uzme njih petoro, niko od njih neće da spava, svi se deru, njihovi roditelji, odnosno moje sestre i braća ne mogu da ih smire, kad mama „opa cupa“ svih petoro, zagrli, zgrabi ako treba, zapeva ili priča bajke i svi se smire. Ako će neko da uspe, onda će ona. Pa će da se takmiče mališani ko će da joj se smesti dublje u krilo. Ona stvarno ima taj neki čudesan dodir za decu. I priče, knjige... kao što je nama čitala od malena, svi oko nje, i ona otvara knjige i čita i čita, to mi je neki njen simbol, priče, knjige, baš taj deo. A pričala je, možete misliti, sve drugačije nego otac. Živo, sa hiljadu glasova, uvek sa nekim pevanjem ili vriskanjem. Kad čita, oči se dečije šire do beskraja. Bliski smo, svako na svoj način sa mamom. Nas dve imamo zajedničko i ljubav prema književnosti. Ona je bibliotekarka, ja sam studirala književnost, možda smo nas dve u porodici najviše sklone ka poeziji, umetnosti u rečima, povezuje nas i ta neka emotivnost, životna osetljivost. Kad može nekad, ne znaš odakle, da te tako dodirne, kad te tako dodirne svet, čovek, društvo, nešto van tebe, tu venu imam po mami... Lepa je moja Marinka, super mama, ne znam kako uspeva. Kako smo starije, mi žene, mislim ćerke, samo je gledamo i pitamo je: kako ste mogli to, kako ste mogli ono, kad ste bili vi, kad ste pričali, kako ste mogli...

Beograd, septembra 2019. Razgovor vodila Helena Rill 
Citirana litertura

Jambrešić Kirin, Renata. 2008. Dom i svijet. Zagreb: Centar za ženske studije.

Stevanović, Lada. 2009. „Rekonstrukcija sećanja, konstrukcija pamćenja: Kuća cveća i Muzej istorije Jugoslavije“. U Spomen mesta, istorija, sećanje : zbornik radova, ur. Aleksandra Pavićević, 101-117. Beograd: Etnografski institut SANU.

Preporučena literatura

Bracić, Milica, Milica Mima Ružičić Novković i Svenka Savić, prir. 2009. Životne priče žena sa invaliditetom u Vojvodini. Novi Sad: Futura publikacije i Ženske studije i istraživanja.

Ćetković, Nadežda i Dobrila Sinđelić-Ibrajter. 2000. Dunavske Švabice. Beograd: Medijska knjižara Krug.

Ferkova, Antonija, Jarmila Hodoličova, Ana Jaškova i Veronika Mitro, prir. 2003. Slovenky: životné príbehy Sloveniek vo Vojvodine. Novi Sad: Futura publikacije i Ženske studije i istraživanja.

Jankov, Edita, prir. 2006. Jevrejke: životne priče žena iz Vojvodine. Novi Sad: Futura publikacije i Ženske studije i istraživanja.

Kesli, Elizabet, prir. 2002. Žene sa Kosova: životne priče Albanki. Novi Sad: Futura publikacije i Ženske studije i istraživanja.

Malešević, Miroslava. 2004. Didara: životna priča jedne Prizrenke. Beograd: Srpski genealoški centar.

Radović, Nadežda, Dobrila Sinđelić-Ibrajter i Vesna Weiss, ur. 2001. Dunavske Švabice II. Veternik: LDIJ.

Rill, Helena i Tamara Šmidling, ur. 2010. Slike tih vremena: životne priče veterana/veteranki i članova/članica njihove porodice. Beograd: Centar za nenasilnu akciju.

Savić Svenka, Marija Aleksandrović, Stanka Dimitrov i Jelena Jovanović, prir. 2001. Romkinje: biografije starih Romkinja u Vojvodini. Novi Sad: Futura publikacije i Ženske studije i istraživanja.

Savić, Svenka, Veronika Mitro, Sara Savić i Marijana Čanak. 2006. „A što ću ti ja jadna pričat...“. Novi Sad: Futura publikacije i Ženske studije i istraživanja.

Savić, Svenka i Veronika Mitro, prir. 2006. Životne priče vojvođanskih Mađarica. Novi Sad: Futura publikacije i Ženske studije i istraživanja.

Savić, Svenka, prir. 2007. Romkinje 2. Novi Sad: Futura publikacije i Ženske studije i istraživanja.

Savić, Svenka i Laura Spariosu, prir. 2011. Životne priče žena u Vojvodini Rumunke. Novi Sad: Futura publikacije i Ženske studije i istraživanja.

Savić, Svenka, prir. 2015. Profesorke Univerziteta u Novom Sadu - životne priče. Novi Sad: Futura publikacije i Ženske studije i istraživanja.

Savić, Svenka. 2018. Erika Marjaš. Novi Sad: Futura publikacije i Ženske studije i istraživanja. 
Simin Bošan Magda i Nevena Simin. 2009. Zašto su ćutale majka i ćerka u istom ratu. Novi sad: Futura publikacije i Ženske studije i istraživanja.

Stojaković, Gordana, prir. 2001. Neda: jedna biografija; životna priča Nede Božinović. Novi Sad: Futura publikacije i Ženske studije i istraživanja.

Stojaković, Gordana, prir. 2001. Znamenite žene Novog Sada. Novi Sad: Futura publikacije i Ženske studije i istraživanja.

Tot Marija, Veronika Mitro, Irina Gardi-Kovačević, Slavica Senderak i Karolina Džudžar. 2003. Ruskini: životni pripovedki. Novi Sad: Futura publikacije i Ženske studije i istraživanja.

\author{
Helena Rill \\ Center za nenasilno akcijo (CNA) \\ Beograd, Srbija \\ helena.rill@gmail.com \\ Lada Stevanović \\ Etnografski inštitut SAZU \\ Beograd, Srbija \\ lada.stevanovic@gmail.com
}

\title{
KOMPLEKSNE POTI ČLOVEŠKIH USOD: JIH JE MOGOČE ZNANSTVENO PREPOZNATI?
}

Besedilo predstavlja uvodno in teoretično obravnavno raziskovanja migracij (iz Slovenije v Srbijo) po metodi ustmenih intervjujev, tj. pogovorov z ženskami v okviru projekta ustmene zgodovine, $\mathrm{k}$ ga je začela Helena Rill. Projekt in pogovori so namenjeni razkrivanju »druge«, tj. intimne plati migracijske medalje, ki se ne zadovolji s splošnimi pripovedmi o številkah, datumih in itinerarjih migrantov. Izhajajoč iz pojma migracije srca, ki ga je etnolog Dušan Drljača ${ }^{4}$ uvedel kot termin, ki se nanaša na selitve, motivirane z ljubeznijo, je $\mathrm{v}$ članku predlagana njegova pomenska razširitev in osvetljeno dejstvo, da vsaka migracija, najsi bo nujna ali prostovoljna, nenadna ali dolgo načrtovana, $v$ človeški duši pušča trajne spremembe in sledi. Za razumevanje zasebnih in individualnih spominov in izpovedi je značilno, da so ti pogosto izredno zapleteni in se le stežka vključujejo v javne (uradne) pripovedi. To je tudi razlog za obravnavo pojmov spomina kot kolektivnega fenomena (ustvarjenega »od zgoraj«) in spominjanja kot nekaj intimnega, zasebnega in posameznega.

Ključne besede: migracija, ustmena zgodovina, ženske, spominjanje

\footnotetext{
${ }^{4}$ Termin je pri nas prevzet iz poljske literature $\mathrm{v}$ sedemdesetih letih preteklega stoletja.
} 
Helena Rill

Centre for Nonviolent Action (CNA)

Belgrade, Serbia

helena.rill@gmail.com

Lada Stevanović

Etnographical institute SASA

Belgrade, Serbia

lada.stevanovic@gmail.com

\section{COMPLEX TRAJECTORIES OF HUMAN DESTINIES: IS IT POSSIBLE TO IDENTIFY THEM USING SCIENTIFIC METHODS?}

The paper is an introductory and theoretical analysis of the study of migrations (from Slovenia to Serbia) using the method of oral interviews, i.e. conversations with women as part of an oral history project, started by Helena Rill. The project and the conversations are designed to reveal the »other «, the intimate side of migrations, which is not limited to public narratives about the numbers, dates, and migration itineraries. Building upon the concept of migrations of the heart ${ }^{5}$, introduced by the ethnologist Dušan Drljača to denote love-motivated migrations, the paper suggests that the meaning of the term should be expanded and highlights the fact that any migration, no matter whether forced or voluntary, sudden or carefully planned, makes lasting changes and leaves traces in the human soul. The fact that individual and personal memory testimonials are often far more complicated and more difficult to fit into public narratives is important for their understanding. This is the reason why the concepts of memory as a collective phenomenon (created from above) and memory as something intimate, personal and individual are also discussed.

Keywords: migrations, oral histories, women, memory

Primljeno / Prejeto: 28. 05. 2020.

Prihvaćeno / Sprejeto: 04.12. 2020.

\footnotetext{
${ }^{5}$ The term was adopted from Polish literature in the 1970s.
} 